\title{
Using Statistical Downscaling to Quantify the GCM-Related Uncertainty in Regional Climate Change Scenarios: A Case Study of Swedish Precipitation
}

\author{
Deliang CHEN ${ }^{* 1,2}$, Christine ACHBERGER ${ }^{1}$, Jouni RÄISÄNEN ${ }^{3}$, and Cecilia HELLSTRÖM ${ }^{1}$ \\ ${ }^{1}$ Earth Sciences Centre, Gothenburg University, Gothenburg, Sweden \\ ${ }^{2}$ Laboratory for Climate Studies/National Climate Center, China Meteorological Administration, Beijing, China \\ ${ }^{3}$ Department of Atmospheric Sciences, University of Helsinki, Finland
}

(Received 25 January 2005; revised 11 August 2005)

\begin{abstract}
There are a number of sources of uncertainty in regional climate change scenarios. When statistical downscaling is used to obtain regional climate change scenarios, the uncertainty may originate from the uncertainties in the global climate models used, the skill of the statistical model, and the forcing scenarios applied to the global climate model. The uncertainty associated with global climate models can be evaluated by examining the differences in the predictors and in the downscaled climate change scenarios based on a set of different global climate models. When standardized global climate model simulations such as the second phase of the Coupled Model Intercomparison Project (CMIP2) are used, the difference in the downscaled variables mainly reflects differences in the climate models and the natural variability in the simulated climates. It is proposed that the spread of the estimates can be taken as a measure of the uncertainty associated with global climate models. The proposed method is applied to the estimation of global-climate-model-related uncertainty in regional precipitation change scenarios in Sweden. Results from statistical downscaling based on 17 global climate models show that there is an overall increase in annual precipitation all over Sweden although a considerable spread of the changes in the precipitation exists. The general increase can be attributed to the increased large-scale precipitation and the enhanced westerly wind. The estimated uncertainty is nearly independent of region. However, there is a seasonal dependence. The estimates for winter show the highest level of confidence, while the estimates for summer show the least.
\end{abstract}

Key words: Statistical downscaling, global climate model, climate change scenario, uncertainty

\section{Introduction}

Climate varies at a variety of spatial scales. Regional (around $10^{1} \mathrm{~km}$ ) is important for many climatic processes. Also, this is a scale that has a great implication for many applications. For example, to enable impact assessments of climate change on agriculture, forestry and energy production, regional climate change scenarios are needed. Such scenarios are not readily available from General Circulation Models (GCMs) with their current resolution (a few $10^{2}$ $\mathrm{km})$. Therefore various techniques of downscaling GCM scenarios have been developed (Hewitson and Crane, 1996). Two commonly used methodologies are statistical downscaling and nesting of regional climate models (RCMs) within GCMs (Murphy, 2000; Fan et al., 2005).

Statistical downscaling has been extensively used to derive regional climate change scenarios in addition to dynamical downscaling in Nordic countries (Hanssen-Bauer et al., 2005). It is essential that any future scenario include an assessment of the uncertainties associated with the prediction (Giorgi and Francisco, 2000; Christensen et al., 2001). There are various techniques developed for estimating uncertainty (Katz, 2002). When statistical downscaling is used to derive future climate changes, uncertainties in the regional scenarios can be caused by uncertainty associated with the driving general circulation model (GCM), errors in the historical data used to build

\footnotetext{
*E-mail: deliang@gvc.gu.se
} 
the downscaling model, the model (both GCM and statistical model) misrepresentations (Benestad, 2001; 2002), and shortcomings of the driving forcings to the GCM. One important source of uncertainty comes from the uncertainty in the GCM predictions that mainly results from the uncertain projection of future greenhouse gas emissions, omission of other climate forcings, stochastic fluctuations of the climate system, and model deficiency. The last problem may to some extent be evaluated by comparing the models' ability to simulate the present climate (e.g., Busuioc et al., 2001a). However, it is difficult to assess how well a model simulates future climate.

One way to evaluate the uncertainty in regional climate scenarios associated with GCMs is to examine the difference between scenarios obtained by using the same predictors from different GCMs with the same statistical downscaling model. The standardized experiments of the CMIP2, the second phase of the Coupled Model Intercomparison Project (Meehl et al., 2000), provide an excellent opportunity to study the impact of the various GCM outputs on the statistically downscaled scenarios. This case study provides an application of this idea to Swedish precipitation scenarios by using a total of 17 GCMs from CMIP2.

Recently, statistical downscaling techniques have been successfully used in Sweden to construct future regional climate scenarios (e.g., Linderson et al., 2004). Although the dynamical downscaling with a regional climate model gives comparable results with that of the statistical downscaling over Sweden (Hellström et al., 2001) and the dynamical downscaling has the advantage of being physically based, the statistical downscaling does have the advantage of being simple and computationally inexpensive. This feature is utilized here to help assess the uncertainties in the precipitation scenarios for Sweden that are associated with the GCMs of the CMIP2.

\section{Models and data used}

\subsection{The downscaling model and the data used}

In this study, a regression-based model was used. A number of large-scale variables were tested for their usefulness to describe the relation between monthly large-scale circulation and precipitation data and local monthly precipitation statistics in Sweden. Multiple regression was applied to establish links between the predictors (large-scale climate variables) and predictand (local precipitation statistics). All the models were developed using the same predictors regardless of season or region. Monthly models were developed to account for variations in the precipitation-forming processes that may depend on season. The statistical downscaling models link monthly precipitation at the 42 Swedish stations shown in Fig. 1 with the large-scale atmospheric circulation and precipitation over Northern Europe shown in Fig. 2. The circulation is described by three indices containing information about geostrophic wind and vorticity over Scandinavia. They include the westerly $(u)$ and southerly $(v)$ components of the geostrophic wind and the total vorticity $(\xi)$. Figure 2 plots the predictor region with Sweden in the center. For a detailed description of the definition and calculation of the indices, the reader is referred to Chen (2000). This set of atmospheric circulation indices now covers the period of 1780-2000, which provides a useful climatology to study impacts of large-scale atmospheric forcing on regional climate and environment (Blenckner and Chen, 2003; Omstedt and Chen, 2001; Chen and Li, 2004). Many studies have dealt with the link between circulation and surface climate in the Nordic countries. The atmospheric circulation patterns including the zonal and meridional flows and the cyclonic/anticyclonic patterns largely influence the temporal variability of precipitation in Sweden (Busuioc et al., 2001b; Johansson and Chen, 2003). These studies justify the use of the three indices as the vorticity describes the strength of the cyclonic/anticyclonic circulations. The fourth predictor, the large-scale precipitation, is an average over the area between $55^{\circ} \mathrm{N}$ and $70^{\circ} \mathrm{N}$ and between $10^{\circ} \mathrm{E}$ and $25^{\circ} \mathrm{E}$ (Fig. 2). In developing a statistical downscaling model for precipitation in southern Sweden, Linderson et al. (2004) also used the large scale precipitation as a predictor in order to capture the eventual signal from climate change and other processes besides the atmospheric circulation. The model development and validation closely follows Hellström et al. (2001) and Hellström and Chen (2003), with the only difference being that the forth predictor is precipitation rather than humidity. We use precipitation instead of humidity because of the data availability from the CMIP2 project. However, the large scale precipitation and humidity have a similar function in carrying the climate change signals for the statistical model.

The statistical downscaling model was developed for each month for amomalies of the monthly predictors and predictant (precipitation). The NCEP reanalysis data (Kalnay et al., 1996) were used to create the predictors for the period 1958-1997. The precipitation data used for fitting the statistical model and for verification of the control simulations are the monthly time series of measurements at 42 Swedish stations from 1958 to 1997 . The data have been homogenized/corrected through the North Atlantic Climatological Dataset (NACD) program (Frich et al., 1996). The data have recently been updated and provided by the Swedish Meteorological and Hydrological Institute (SMHI). For details of the model development and verification, the reader is refered to Hellström et al. (2001). 


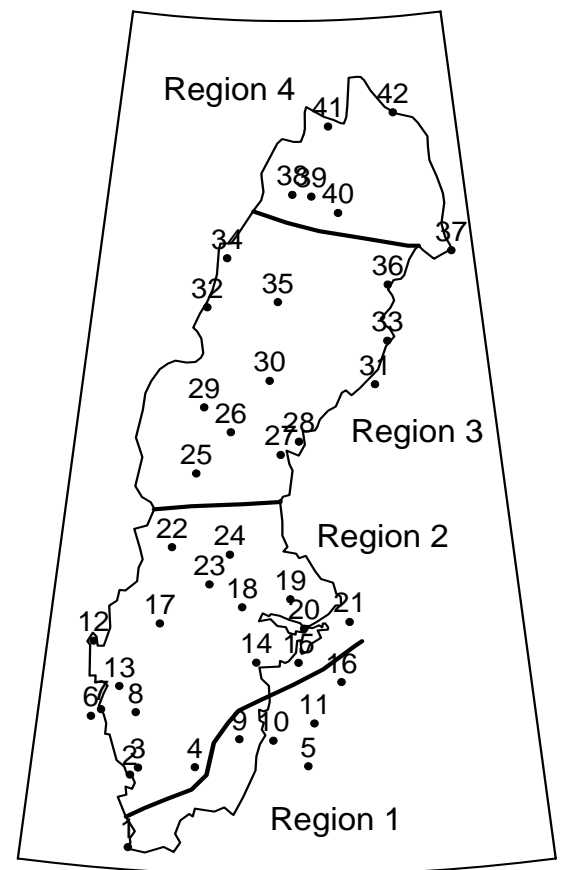

Fig. 1. The 42 precipitation stations over Sweden and the four regions used.

\subsection{The CMIP2 dataset}

CMIP2 is an intercomparison of standard transient climate change experiments by coupled atmosphereocean general circulation models. Each CMIP2 experiment consists of an 80-year control run with constant ("present-day") $\mathrm{CO}_{2}$ concentration and an 80-year enhanced greenhouse run in which $\mathrm{CO}_{2}$ increases $1 \%$ per year compound, doubling in 70 years. In this study, 17 CMIP2 models are used: BMRC (Power et al., 1993),

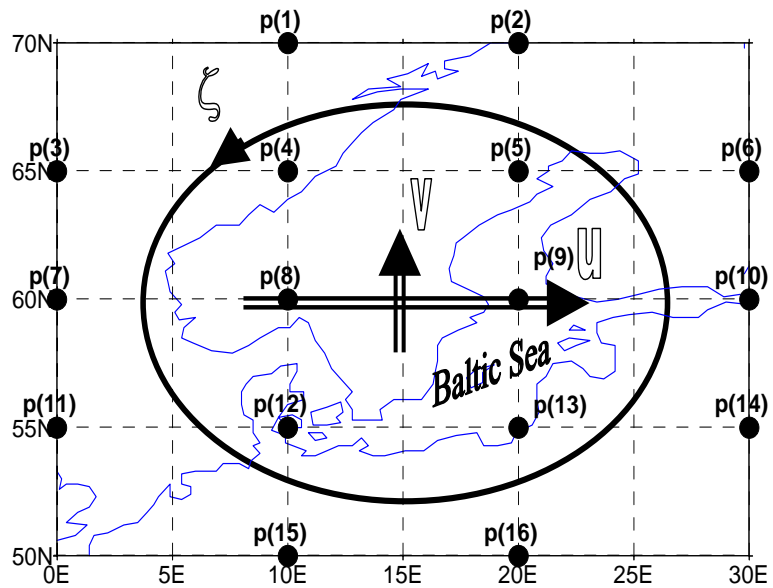

Fig. 2. The map showing the predictor domain of the statistical model. The 16 points indicate the sea level pressure data used in calculating the circulation indices which are denoted by the wind and vorticity symbols in the figure.
CCC (Flato et al., 2000), CCSR/NIES (Emori et al., 1999), CERFACS (Barthelet et al., 1998), CSIRO (Hirst et al., 2000), GFDL (Manabe et al., 1991), GISS (Russell and Rind, 1999), IAP/LASG (Zhang et al., 2000), LMD/IPSL (Braconnot et al., 1997), MPI-ECHAM3 (Voss et al., 1998), MPI-ECHAM4 (Roeckner et al., 1999), MRI (Tokioka et al., 1995), NCAR-CSM (Boville and Gent, 1998), NCAR/DOEPCM (Washington et al., 2000), NCAR-WM (Washington and Meehl, 1996), UKMO-HadCM2 (Johns et al., 1997) and UKMO-HadCM3 (Gordon et al., 2000).

The GCM-simulated changes in the predictor variables are estimated by comparing the last 30-year period in the enhanced greenhouse runs (the doubling of $\mathrm{CO}_{2}$ occurs 10 years before the end of this period) with the whole period in the control runs (80-year means). Thus, the last 30 years of the CMIP2 scenario approximately represent the period when the doubling of the present day $\mathrm{CO}_{2}$ is reached. The difference between the future and present climates can be considered as a response to the doubled $\mathrm{CO}_{2}$. The simulated global mean warming at this time ranges from $1.2^{\circ} \mathrm{C}(\mathrm{NCAR}$ $\mathrm{PCM})$ to $3.4^{\circ} \mathrm{C}$ (NCAR-WM), with a 17 -model mean of $1.7^{\circ} \mathrm{C}$, and the change in global precipitation from $-0.2 \%$ (ECHAM4) to $4.1 \%$ (GFDL) with a mean of $2.2 \%$.

\section{Results}

The changes of seasonal (DJF=winter, $M A M=$ spring, JJA=summer and $\mathrm{SON}=$ autumn) mean predictors and predictant (precipitation) are calculated. Changes in annual precipitation are then computed based on the seasonal values.

\subsection{Changes in the predictors}

Once the statistical downscaling model is established, differences in the scenarios can only be caused by differences in the predictors. An examination of the simulated changes in the predictors can therefore be helpful in interpreting differences in the downscaled precipitation. Figure 3 shows seasonal changes in the four predictors between the enhanced greenhouse run and the control run. The majority of models indicate an increase in westerly wind. More advection from the westerly direction would mean, if acting alone, higher temperature and precipitation for Sweden (Chen and Hellström, 1999; Busuioc et al., 2001b). On the other hand, changes in southerly wind are less clear; there are both increases and decreases, though there is an overall decrease during summer. For the vorticity, little if any systematic change is visible. Finally, the large-scale precipitation displays an overwhelming in- 

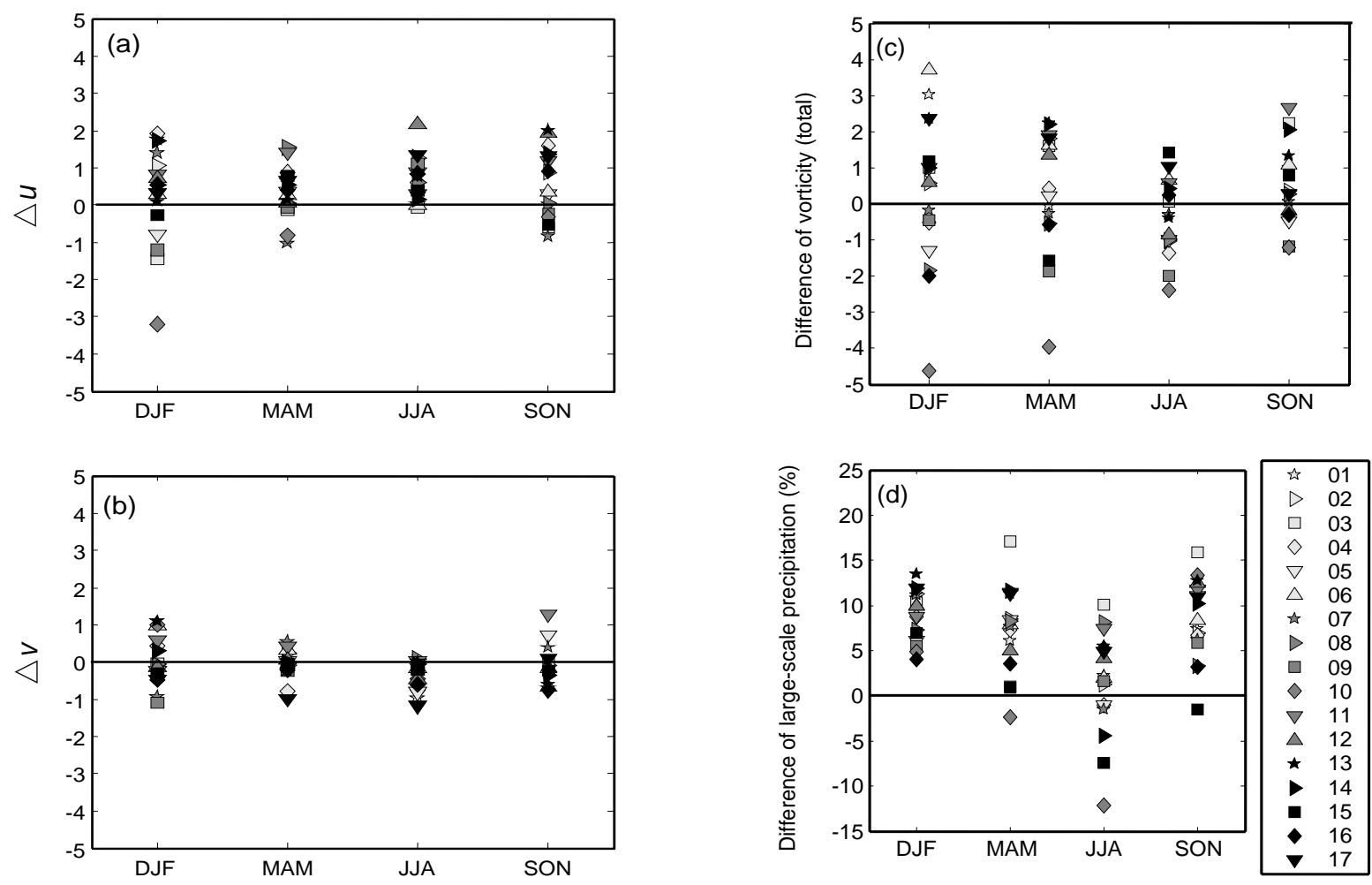

Fig. 3. Differences in the seasonal means of the predictors from the GCMs between the control and scenario runs: (a) the $u$-wind, (b) the $v$-wind, (c) the vorticity, (d) the large scale precipitation. Models used: 01 $=\mathrm{CCC}, 02=\mathrm{CERFACS}, 03=\mathrm{CSIRO}, 04=\mathrm{MPI} / \mathrm{ECHAM} 3,05=\mathrm{GFDL}, 06=\mathrm{GISS}, 07=\mathrm{LMD} / \mathrm{IPSL}, 08=\mathrm{MRI}$, 09=NCAR-CSM, $10=$ NCAR-WM, 11=UKMO-HadCM2, 12=BMRC, $13=\mathrm{CCSR} / \mathrm{NIES} ; 14=\mathrm{MPI} / \mathrm{ECHAM} 4$; $15=\mathrm{IAP} / \mathrm{LASG}, 16=\mathrm{NCAR} / \mathrm{DOE}-\mathrm{PCM}, 17=\mathrm{UKMO}-\mathrm{HadCM} 3$.

creasing trend, with exceptions almost entirely confined to summer.

\subsection{Changes in the downscaled precipitations}

To examine the regional changes, the downscaled station precipitation was grouped into four regions according to Busuioc et al. (2001b) and Hellström et al. (2001), as shown in Fig. 1. The changes in the seasonal and annual means are calculated for the four regions in Sweden and are expressed in percent of the control climate. The mean changes for all the regions were calculated as averages of all stations situated in the respective regions. The mean change all over Sweden was computed as the average of the four regional means. Figure 4 shows the results. A considerable spread in the predictors, especially in the circulation indices, is reflected as a spread in the downscaled precipitation changes. However, the differences in the scenarios are fairly consistent between the regions, that is, some models indicate relatively high and some relatively low changes in the whole of Sweden. The spread of different scenarios depends much more on season than on region.

Figure 4 shows the seasonal means of all the sce- narios and the associated standard deviation for the four regions and for the whole of Sweden. If of all the GCMs can be considered to be of equal reliability, the mean of the changes may be taken as an estimate of the most likely change and the standard deviation as a measure of uncertainty in this estimate. The average change in the annual precipitation is in all regions positive and larger than the standard deviation. The increase in northern Sweden is higher than in the south. However, there is a considerable seasonal variation in the changes. While precipitations in autumn, winter and summer are expected to increase, the summer precipitation exhibits (on average) a decrease in the two southern regions.

\section{Discussions and conclusions}

The uncertainty associated with GCMs in statistical downscaling may be evaluated by examining the differences in the predictors and especially in the downscaled climate changes. For standardized GCM simulations, the difference resulting from different forcings can be neglected, and the difference in the downscaled variables will mainly reflect differences in 

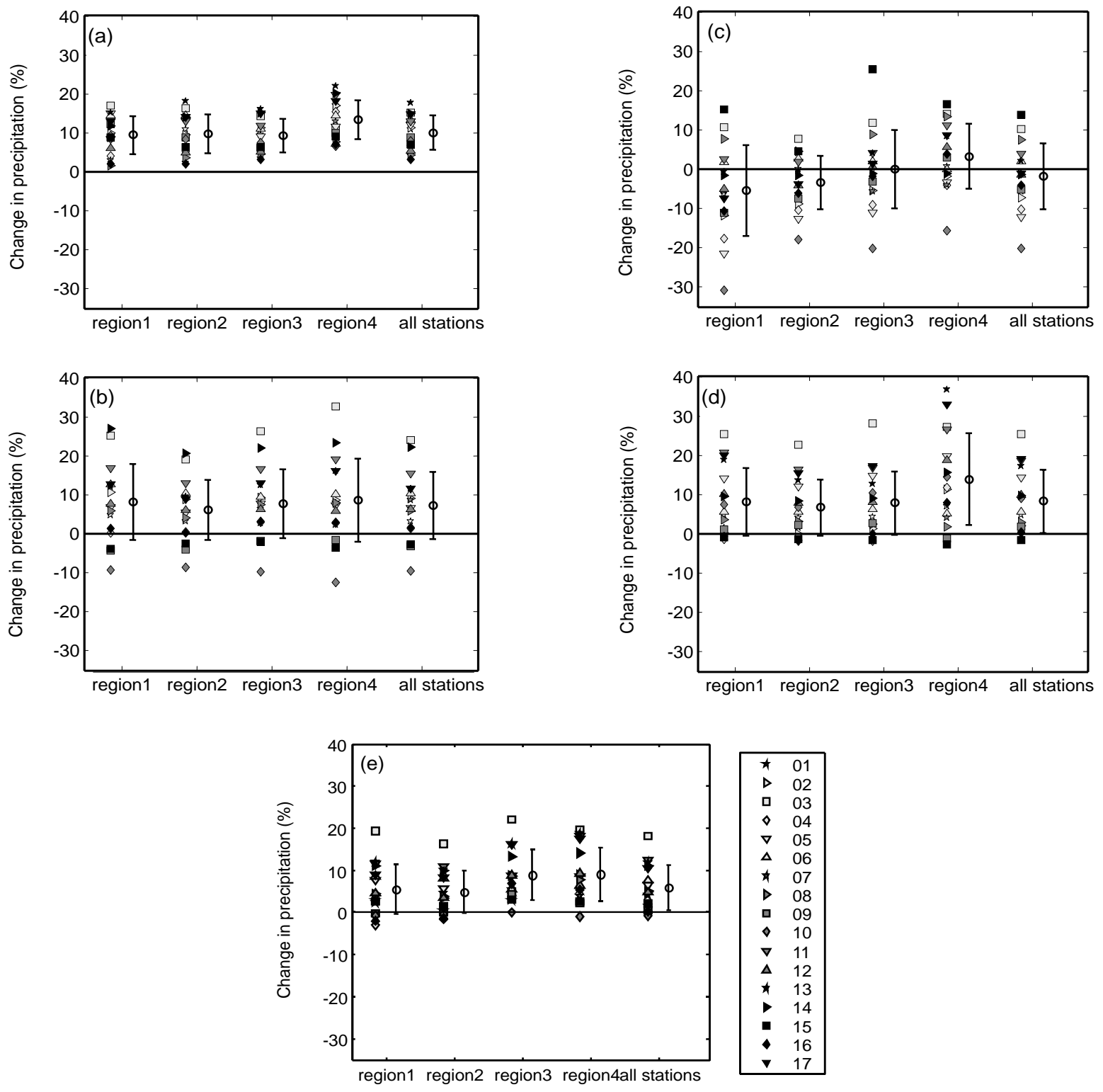

Fig. 4. Regional changes (\%) in the downscaled precipitation for the four regions and for the whole of Sweden. Region $1=$ southernmost, Region $2=$ south, Region $3=$ north, Region $4=$ northernmost. Seasonal plots for (a) DJF, (b) MAM, (c) JJA, (d) SON and (e) annual plot are made. The models used are the same as those indicated in Fig. 3. The mean and the error bars ( \pm one standard deviation) of the changes in the 17 GCMs are also plotted.

the GCMs and the natural variability in the simulated climate. However, it should be kept in mind that differences in GCMs are expressed only by the differences in the predictors, and the statistical model is not a perfect one. The first point implies that the reliability of GCMs for this exercise is only dependent on how well these predictors are simulated. While the simulation of these predictors for the present climate may be verified by observations, it is difficult to judge the simulation for the future. This makes the use of all available GCMs meaningful. The second point (defi- ciencies in the statistical model) has implications for the interpretation of the changes in the downscaled variables that are determined by the combination of predictors. These changes, and the differences in them arising from different GCMs, can be either amplified or reduced due to the misrepresentation of the statistical model. Again, statistics from all available GCMs should be helpful in getting closer to the reality.

For the assessment on the uncertainty for the Swedish precipitation, the following conclusions can be drawn from the case study: 
(1) There is an overall increase in annual precipitation all over Sweden based on a majority of the 17 GCMs used. The increase is more significant in northern than in southern Sweden.

(2) This overall positive trend can be attributed to the increased large-scale precipitation and the westerly wind.

(3) The seasonal precipitations in autumn, winter and spring are expected to increase, whereas there is an indication of decreasing summer precipitation in the southern half of the country.

(4) The estimated uncertainty is nearly independent of region. However, there is a seasonal dependence. The estimates for winter show the highest level of confidence, and the estimates for the summer season show the least.

Acknowledgments. This work is part of the Swedish Regional Climate Modelling Programme (SWECLIM) that is financed by MISTRA and SMHI. Deliang Chen is also supported by the Swedish Research Council, the Chinese Academy of Sciences and the China Meteorological Administration.

\section{REFERENCES}

Barthelet, P., L. Terray, and S. Valcke, 1998: Transient $\mathrm{CO}_{2}$ experiment using the ARPEGE/OPAICE non flux corrected coupled model. Geophys. Res. Lett., 25, $2277-2280$.

Benestad, R. E., 2001: A comparison between two empirical downscaling strategies. International Journal of Climatology, 21, 1645-1668.

Benestad, R. E., 2002: Empirically downscaled multimodel ensemble temperature and precipitation scenarios for Norway. J. Climate, 15, 3008-3027.

Blenckner, T., and D. Chen, 2003: Comparison of the impact of regional and North Atlantic atmospheric circulation on an aquatic ecosystem. Climate Research, 23, 131-136.

Boville, B. A., and P. R. Gent, 1998: The NCAR Climate System Model, Version One. J. Climate, 11, 11151130.

Braconnot, P., O. Marti, and S. Joussaume, 1997: Adjustment and feedbacks in a global coupled oceanatmosphere model. Climate Dyn., 13, 507-519.

Busuioc, A., D. Chen, and C. Hellström, 2001a: Performance of statistical downscaling models in GCM validation and regional climate change estimates: Application for Swedish precipitation. Interational Journal of Climatology, 21, 557-578.

Busuioc, A., D. Chen, and C. Hellström, 2001b: Temporal and spatial variability of precipitation in Sweden and its link with the large scale atmospheric circulation. Tellus, 53A, 348-367.

Chen, D., and C. Hellström, 1999: The influence of the North Atlantic Oscillation on the regional temperature variability in Sweden: Spatial and temporal variations. Tellus, 51A, 505-516.
Chen, D., 2000: A monthly circulation climatology for Sweden and its application to a winter temperature case study. International Journal of Climatology, 20, $1067-1076$

Chen, D., and X. Li, 2004: Scale dependent relationship between maximum ice extent in the Baltic Sea and atmospheric circulation. Global and Planetary Change, 41, 275-283.

Christensen, J.-H., J. Räisänen, T. Iversen, D. Bjørge, O. B. Christensen, and M. Rummukainen, 2001: A synthesis of regional climate change simulations. A Scandinavian perspective. Geophys. Res. Lett., 28, 10031006.

Emori, S., T. Nozawa, A. Abe-Ouchi, A. Numaguti, M. Kimoto, and T. Nakajima, 1999: Coupled oceanatmosphere model experiments of future climate change with an explicit representation of sulfate aerosol scattering. J. Meteor. Soc. Japan, 77, 12991307.

Fan, L., C. Fu, and D. Chen, 2005: A survey on statistical downscaling in climate studies. Advance in Earth Sciences, 20(3), 320-329. (in Chinese)

Flato, G. M., G. J. Boer, W. G. Lee, N. A. McFarlane, D. Ramsden, M. C. Reader, and A. J. Weaver, 2000: The Canadian Centre for Climate Modelling and Analysis Global Coupled Model and its climate. Climate Dyn., 16, 451-467.

Frich, F., and Coauthors, 1996: North Atlantic Climatological Dataset (NACD Version 1)- Final Report. DMI Report, Copenhagen, Denmark, 47pp.

Giorgi, F., and R. Francisco, 2000: Evaluating uncertainties in the prediction of regional climate change. Geophys. Res. Lett., 27, 1295-1298.

Gordon, C., C. Cooper, C. A. Senior, H. Banks, J. M. Gregory, T. C. Johns, J. F. B. Mitchell, and R. A. Wood, 2000: The simulation of SST, sea ice extents and ocean heat transports in a version of the Hadley Centre Coupled Model without flux adjustments. Climate Dyn., 16, 147-168.

Hanssen-Bauer, I., C. Achberger, R. Benestad, D. Chen, and E. Førland, 2005: Empirical-statistical downscaling of climate scenarios over Scandinavia: A review. Climate Research, 29, 255-268.

Hellström, C., and D. Chen, 2003: Statistical downscaling based on dynamically downscaled predictors: Application to monthly precipitation in Sweden. Adv. Atmos. Sci., 20, 951-958.

Hellström, C., D. Chen, C. Achberger, and J. Räisänen, 2001: A comparison of climate change scenarios for Sweden based on statistical and dynamical downscaling of monthly precipitation. Climate Research, 19, $45-55$.

Hewitson, B. C., and R. C. Grane, 1996: Climate downscaling: Techniques and application. Climate Research, 7(2), 85-95.

Hirst, A., S. P. O'Farrell, and H. B. Gordon, 2000: Comparison of a coupled ocean-atmosphere model with and without oceanic eddy-induced advection. Part I: Ocean spinup and control integrations. J. Climate, 13, 139-163.

Johansson, B., and D. Chen, 2003: The influence of wind and topography on precipitation distribution. A case study in Sweden. Internation Journal of Climatology, 23, 1523-1535. 
Johns, T. C, R. E. Carnell, J. F. Crossley, J. M. Gregory, J. F. B. Mitchell, C. A. Senior, S. F. B. Tett, and R. A. Wood, 1997: The second Hadley Centre Coupled ocean-atmosphere GCM: Model description, spinup and validation. Climate Dyn., 13, 103-134.

Katz R. W., 2002: Techniques for estimating uncertainty in climate change scenarios and impact studies. $\mathrm{Cli}$ mate Research, 20, 167-185.

Linderson, M.-L., C. Achberger, and D. Chen, 2004: Statistical downscaling and scenario construction of precipitation in Scania, southern Sweden. Nordic Hydrology, 35, 261-278.

Manabe, S., R. J. Stouffer, M. J. Spelman, and K. Bryan, 1991: Transient responses of a coupled oceanatmosphere model to gradual changes of atmospheric $\mathrm{CO}_{2}$. Part I: Annual mean response. J. Climate, 4, 785-818.

Meehl, G. A., G. J. Boer, C. Covey, M. Latif, and R. J. Stouffer, 2000: The Coupled Model Intercomparison Project (CMIP). Bull. Amer. Meteor. Soc., 81, 313318.

Murphy, J., 2000: Predictions of climate change over Europe using statistical and dynamical downscaling techniques. Internation Journal of Climatology, 20, 489-501.

Omstedt, A., and D. Chen, 2001: Influence of atmospheric circulation on the maximum ice extent in the Baltic Sea. J. Geophys. Res., 106, 4493-4500.

Power, S. B., R. A. Colman, B. J. McAvaney, R. R. Dahni, A. M. Moore, and N. R. Smith, 1993: The BMRC coupled atmosphere/ocean/sea-ice model. BMRC Research Report No. 37, Bureau of Meteorology Research Centre, Melbourne, Australia, 58pp.

Roeckner, E., L. Bengtsson, J. Feichter, J. Lelieveld, and H. Rodhe, 1999: Transient climate change simulations with a coupled atmosphere-ocean GCM including the tropospheric sulfur cycle. J. Climate, 12, 3004-3032.

Russell, G. L., and D. Rind, 1999: Response to $\mathrm{CO}_{2}$ transient increase in the GISS coupled model: Regional coolings in a warmer climate. J. Climate, 12, 531539 .

Tokioka, T., A. Noda, A. Kitoh, Y. Nikaidou, S. Nakagawa, T. Motoi, S. Yukimoto, and K. Takata, 1995: A transient $\mathrm{CO}_{2}$ experiment with the MRI CGCM. Quick Report. J. Meteor. Soc. Japan, 73, 817-826.

Voss, R., R. Sausen, and U. Cubasch, 1998: Peridiocally synchronously coupled integrations with the atmosphere-ocean general circulation model ECHAM3/LSG. Climate Dyn., 14, 249-266.

Washington, W. M., and G. A. Meehl, 1996: High-latitude climate change in a global coupled ocean-atmospheresea ice model with increased atmospheric $\mathrm{CO}_{2} . J$. Geophys. Res., 101, 12795-12801.

Washington, W. M., and Coauthors, 2000: Parallel climate model (PCM) control and transient simulations. Climate Dyn., 16, 755-774.

Zhang Xuehong, Shi Guangyu, Liu Hui, and Yu Yongqiang, 2000: IAP Global Ocean-Atmosphere-Land System Model. Science Press, Beijing, 252pp. 